\title{
Desain Aplikasi Manajemen Kunjungan Pelanggan Barbershop Squad Corporation (AK-SQUAD)
}

\author{
Husni Faqih ${ }^{1,}$, Aditya Syaiful Islam $^{2}$, Zanuar Rifai ${ }^{3}$, Ayu Amarcia A.S.W ${ }^{4}$ \\ 1,2,4 Universitas Bina Sarana Informatika \\ ${ }^{3}$ Universitas AMIKOM Purwokerto \\ 1 husni.hnf@bsi.ac.id , ${ }^{2}$ adityasy2705@bsi.ac.id , ${ }^{3}$ zanuar.rifai@amikompurwokerto.ac.id, \\ ${ }^{4}$ ayuama12185143@bsi.ac.id
}

\begin{abstract}
Along with the development of social media and growing awareness to look attractive, making business growth in the field of barbershop develop very rapidly not only in big cities and even in the regions. Providing the best service is one of the successful strategies in the service business. One of the best forms of service is providing ongoing information such as discount information. This customer data is obtained from the customer data management system. SQUAD Corporation Pemalang as one of the companies engaged in the field of barbershop services also uses this strategy by using the Ms. Ecxel application. Not using a specific application for customer data management has a lack of difficulty in getting customer data because some customers are reluctant to fill in the visit data. Submission of information is also still manually check the telephone data of each customer. Research uses data collection techniques and software development methods Rapid Application Development (RAD). Data collection techniques by conducting observation activities, interviews and literature study. The results of the study were the design of the Barbershop Squad Corporation (AK-SQUAD) Customer Visit Management Application Design.
\end{abstract}

Keywords: Customer Management, Application, Barbershop, RAD

Abstrak: Seiring perkembangan media sosial dan tumbuhnya kesadaran untuk berpenampilan menarik, membuat pertumbuhan bisnis di bidang barbershop berkembang sangat pesat tidak hanya di kota besar bahkan hingga ke daerah-daerah. Memberikan pelayanan terbaik adalah salah satu strategi sukses dalam bisnis jasa. Salah satu bentuk pelayanan terbaik adalah pemberian informasi secara berkelanjutan seperti informasi diskon. Data pelanggan ini didapat dari sistem pengeolalaan data pelanggan. SQUAD Corporation Pemalang sebagai salah satu perusahaan yang bergerak di bidang jasa barbershop juga menggunakan strategi tersebut dengan menggunakan aplikasi Ms. Excel. Belum menggunakan aplikasi yang khusus untuk pengelolaan data pelanggan memiliki kekurangan pada kesulitan mendapatkan data pelanggan karena sebagian pelanggan enggan mengisi data kunjungan. Penyampaian informasinya juga masih manual cek data telepon setiap pelanggan. Penelitian ini bertujuan untuk menghasilkan sebuah sistem informasi yang nyaman bagi pelanggan dalam mengisi data kunjungan untuk kebutuhan pengembangan layanan Squad Corporation. Penelitian menggunakan teknik pengumpulan data dan metode pengembangan software Rapid Application Development (RAD). Teknik pengumpulan data dengan malakukan kegiatan observasi, wawancara dan studi pustaka. Hasil dari penelitian adalah desain Aplikasi Manajemen Kunjungan Pelanggan Barbershop Squad Corporation (AK-SQUAD).

Kata Kunci: Manajemen Pelanggan, Aplikasi, Barbershop, RAD (1) $5(2) \begin{aligned} & \text { This is an open access article distributed under the Creative Commons Attribution License, which permits } \\ & \text { unrestricted use, distribution, and reproduction in any medium, provided the original work is properly cited. C2019 }\end{aligned}$ by author and IJSE-Indonesian Journal on Software Engineering.

\section{A. PENDAhULUAN}

Seiring perkembangan media sosial dan tumbuhnya kesadaran untuk berpenampilan menarik, membuat pertumbuhan bisnis di bidang barbershop berkembang sangat pesat tidak hanya di kota besar tapi juga hingga ke daerah-daerah. Bisnis barbershop khususnya di 
Kabupaten Pemalang semakin banyak, sehingga persaingan bisnis semakin meningkat. Hal tersebut tentunya membuat pelanggan semakin banyak pilihan dan dengan mudah dapat membandingkan kualitas layanan yang diberikan oleh masing-masing barbershop.

Untuk dapat sukses dalam persaingan bisnis harus memiliki strategi yang tepat dan berbeda dengan yang lain. Persaingan untuk meningkatkan kepuasan pelanggan menjadi perhatian utama pelaku usaha. Orientasi jangka panjang yang menekankan loyalitas pada pelanggan menjadi hal yang amat penting dan harus diperhatikan oleh perusahaan (Alfin \& Nurdin, 2017). Kepuasan pelanggan merupakan dasar penting bagi loyalitas pelanggan, sehingga semakin tinggi kepuasan pelanggan maka loyalitas pelanggan akan meningkat (Setyanta, 2017).

Salah satu perusahaan barbershop yang terkenal di Kabupaten Pemalang adalah SQUAD Corporation. SQUAD Corporation memiliki dua brand barbershop, yaitu Toekang Tjoekoer Barbershop dan SQUAD Barbershop. Kedua barbershop tersebut memiliki strategi untuk meningkatkan pelayanan jasa dengan mengambil data dari pengelolaan data kunjungan pelanggan. Data pelanggan didapat dari kunjungan pelanggan dimana pelanggan mengisi formulir data kunjungan pelanggan yang selanjutnya diiunput admin dengan aplikasi Ms. Excel. Data pelanggan ini akan digunakan untuk memberikan informasi dan promo melalui SMS serta perusahaan mendapatkan masukan-masukan dari pelanggan. Namun strategi ini memiliki kendala, yaitu pelanggan enggan mengisi kertas formulir kunjungan dan pelanggan harus mengisi kembali formulir kunjungan di kunjungan berikutnya.

SQUAD Corporation melihat kendala tersebut sebagai hambatan usaha terutama pada keengganan pelanggan mengisi kertas formulir kunjungan. Hal tersebut mengindikasikan ketidaknyamanan pelanggan. Namun di lain sisi data kunjungan sangat penting bagi perusahaan demi peningkatan pelayanan selanjutnya. Untuk itu dibutuhkan sebuah sistem yang nyaman bagi pelanggan dalam mengisi data kunjungan. Sebagian besar pengunjung adalah pemuda, maka aplikasi website kunjungan pelanggan dibutuhkan oleh perusahaan.

\section{B. TINJAUAN PUSTAKA}

\section{Sistem Informasi}

Jogiyanto mengungkapkan bahwa sistem merupakan kumpulan elemen-elemen yang saling berinteraksi dalam mencapai tujuan tertentu (Faqih \& Avisha, 2017). Informasi merupakan hasil dari pengolahan data yang bermanfaat bagi seseorang. Jadi tidak semua hasil dari pengolahan merupakan informasi, hasil pengolahan data yang tidak bermanfaat bagi seseorang bukanlah merupakan informasi (Darmawan \& Fauzi, 2013:2). Permana menjelaskan bahwa Sistem Informasi adalah suatu sistem di organisasi yang mempertemukan kebutuhan pengolahan transaksi harian, mendukung fungsi operasi organisasi yang bersifat manajerial dengan kegiatan strategi dari suatu organisasi yang bertujuan menyediakan laporan-laporan yang diperlukan oleh pihak luar (Faqih \& Avisha, 2017).

\section{Website}

Syaifullah \& Soemantri menjelaskan bahwa website merupakan keseluruhan halaman web pada sebuah domain yang mengandung informasi (Firmansyah, 2017). Sedangkan aplikasi web (webapp) adalah sebuah aplikasi yang diakses pada web browser melalui jaringan internet atau intranet (Ma'rifati, 2015).

\section{Struktur Navigasi}

Prihatna menjelaskan bahwa Struktur Navigasi merupakan hirarki atau susunan menu suatu situs yang menggambarkan isi setiap halaman dan link atau navigasi halaman pada suatu website. Dimana terdapat 4 jenis bentuk struktur navigasi, yaitu bentuk linear, non-linear, hirarki, dan campuran (Rohman et al, 2018).

\section{Entity Relationship Diagram (ERD)}

Connoly \& Begg mengemukakan bahwa Entity Relation Diagram (ERD) menyediakan 
cara sederhana dalam memahami bagian komponen desain basis data, dan digunakan untuk menggambarkan struktur logika basis data (Malau \& Ariyanto, 2014).

Terdapat tiga (3) komponen sederhana ERD (Brandenburg, 2018), yaitu:

a. Entitas

Pada dasarnya entitas adalah suatu objek. Sedangkan dalam istilah basis data relasional entitas adalah tabel.

b. Atribut

Atribut adalah semua informasi yang berkaitan dengan entitas. Dalam database relasional, atribut diwakili oleh bidang-bidang di mana informasi yang ada di dalam rekaman disimpan.

c. Relasi

Relasi merupakan penghubung antar entitas

\section{METODE PENELITIAN}

\section{Teknik Pengumpulan Data}

Penelitian menggunakan 3 jenis teknik pengumpulan data (Wijaya \& Sari, 2015), antara lain:

a. Observasi

Observasi pada sistem pelayanan dan pendataan pelanggan pada SQUAD Barbershop untuk mengetahui proses sistem berjalan yang sudah diterapkan di tempat riset.

b. Wawancara

Wawancara dengan pemilik Squad Corporation terkait masalah yang diriset untuk mengetahui dan mengumpulkan kebutuhan sistem.

c. Studi Pustaka

Studi Pustaka dengan mencari referensi-referensi dari jurnal-jurnal tentang pembuatan website, Sistem Informasi, dan metode pengembangan sistem RAD yang terkait permasalahan dan tema yang penelitian.

\section{Metode Pengembangan Software}

Metode pengembangan perangkat lunak yang digunakan dalam penelitian ini adalah Rapid Application Development (RAD). Kendall menjelaskan bahwa RAD merupakan pendekatan berorientasi objek pada pengembangan sistem yang mencakup suatu metode pengembangan serta perangkat-perangkat lunak (Ratnawati, Siwi, \& Faqih, 2018). Alasan dari pengambilan metode ini karena metode RAD cocok digunakan dalam pembangunan proyek jangka pendek.

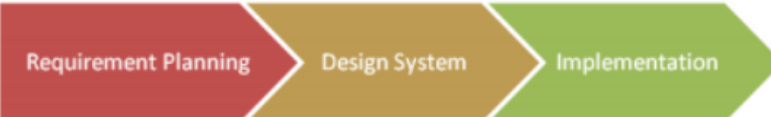

Sumber: Kendal dalam (Wahyuningrum \& Januarita, 2014)

Gambar 1. Tahapan Pengembangan System Model RAD

Ada 3 tahapan dalam RAD menurut Kendal, antara lain:

a. Requirements Planning

User dan Analyst System bertemu untuk mengidentifikasi tujuan dan kebutuhan sistem. Merupakan tahapan terpenting karena terjadi keterlibatan antar kedua belah pihak.

b. Design System

Keaktifan user sangat menentukan dalam pencapaian tujuan karena pada tahap ini melakukan proses design system dan melakukan perbaikan jika terdapat kesalahan atau ketidaksesuaian design antara user dan Analyst System. Output dari tahap ini adalah adalah spesifikasi software, meliputi organisasi sistem secara umum, struktur data dan lain sebagainya. 
c. Implementation

Tahap akhir pasca user dan analyst system menyetujui hasil Design Sytem yang kemudian dieksekusi dengan bahasa pemrograman oleh programmer. Tahap ini juga melakukan testing unit.

\section{HASIL DAN PEMBAHASAN}

\section{Tahap Requirements Planning}

Pada tahap ini menguraikan proses bisnis yang ada dan dilanjutkan dengan tahap analisa kebutuhan sistem.

\section{Analisa Kebutuhan Fungsional}

Terdapat 2 kebutuhan pada analisa kebutuhan fungsional, antara lain:

a. Analisa Kebutuhan Pengguna

Hasil analisa kebutuhan pengguna pada sistem pengelolaan data kunjungan pelanggan SQUAD Corporation terdapat 5 pengguna yang saling berinteraksi dalam lingkungan sistem, yaitu admin sistem, admin cabang, owner, pelanggan dan visitor. Kelima pengguna tersebut memiliki karakteristik interaksi dengan sistem yang berbeda-beda dan memiliki kebutuhan informasi berbeda juga.

1) Admin Sistem

Kebutuhan pengguna admin sistem, yaitu:

a) Admin Sistem dapat mengelola data pada halaman web pelanggan dan admin, tetapi hanya bisa mengakses pada halaman web admin.

b) Admin Sistem dapat memposting berita untuk ditampilkan dihalaman pelanggan.

c) Admin Sistem dapat mengeola seluruh data yang terdapat pada sistem, mulai data pelanggan, data cabang, data karyawan, data layanan, data kunjungan, data admin dan data laporan kemudian mencetaknya apabila dibutuhkan.

2) Admin Cabang

Kebutuhan pengguna admin cabang, yaitu:

a) Admin Cabang hanya dapat mengakses halaman web pelanggan, dan tidak bisa mengakses pada halaman web admin.

b) Admin Cabang dapat mengakses menu yang ada pada halaman web pelanggan, seperti menu beranda, menu profil perusahaan, menu layanan, menu outlet kami, menu gallery dan menu kontak.

c) Admin Cabang dapat melakukan input data kunjungan pelanggan, mengecek data kunjungan, dan jadwal karyawan atau barberman.

3) Owner

Kebutuhan pengguna owner, yaitu:

a) Owner dapat mengakses halaman web admin, dengan cara login memasukan kode dan password yang sudah terdaftar.

b) Pada halaman web admin, owner hanya dapat mengakses menu posting berita, menu laporan dan mencetak data laporan tersebut apabila dibutuhkan.

4) Pelanggan

Kebutuhan pengguna pelanggan, yaitu:

a) Pelanggan dapat mengakses menu beranda, menu profil perusahaan, menu layanan, menu outlet kami, menu gallery, menu kontak dan mengirim pesan lewat chat tanpa harus melakukan login terlebih dahulu.

b) Pelanggan dapat melakukan login dengan memasukan nomor hp dan password yang telah terdaftar.

c) Pelanggan dapat mengelola data profil, mengecek data kunjungan, dan mengecek jadwal karyawan atau barberman setelah melakukan login.

5) Visitor

Kebutuhan pengguna visitor, yaitu: 
a) Visitor dapat mengakses menu beranda, menu profil perusahaan, menu layanan, menu outlet kami, menu gallery, menu kontak, mengirim pesan lewat chat tanpa harus melakukan pendaftaran akun terlebih dahulu.

b) Visitor dapat melakukan input data pada form pendaftaran akun pelanggan untuk kebutuhan login agar data bisa terdaftar sebagai pelanggan pada database sistem dan melakukan akses menu yang lebih banyak.

b. Analisa Kebutuhan Sistem

Hasil analisa kebutuhan sistem, antara lain:

1) Kebutuhan List Menu sistem Aplikasi AK-SQUAD, antara lain:

a) Menu Beranda, menampilkan portal berita yang berisi info tentang berjalannya barbershop yang ada pada manajemen SQUAD Corporation.

b) Menu Profil Perusahaan, menampilkan detail sejarah perusahaan, visi misi perusahaan, dan struktur organisasi perusahaan kepada seluruh pengunjung website.

c) Menu Layanan, menampilkan detail layanan yang ada pada barbershop sehingga pelanggan sebelum datang ke barbershop sudah mengetahui layanan apa saja yang dapat dinikmati.

d) Menu Outlet Kami, menampilkan detail cabang outlet barbershop yang masih satu manajemen dengan SQUAD Corporation baik di dalam kota maupun di luar kota sehingga pelanggan mengetahui barbershop mana yang masih satu yang masih satu manajemen dengan SQUAD Corporation.

e) Menu Gallery, menampilkan foto-foto kegiatan berjalannya barbershop sehingga bisa menjadi referensi pelanggan sebelum datang menikmati layanan di barbershop.

f) Menu Kontak, menampilkan informasi mengenai alamat kantor, nomor hp, dan email. Tersedia juga alamat kantor dalam bentuk google maps untuk memudahkan pelanggan dalam menemukan alamat.

2) Kebutuhan Form Web sistem Aplikasi AK-SQUAD, antara lain:

a) Form Login Pelanggan, digunakan sebagai media login pelanggan yang sudah mempunyai akun pada sistem dengan memasukan nomor hp dan password yang sudah terdaftar dan tersimpan dalam database sistem sebelumnya.

b) Form Pendaftaran Akun Pelanggan, digunakan sebagai media pendaftaran akun baru bagi pelanggan yang belum mempunyai akun pada sistem. Pelanggan diharuskan memasukan beberapa data seperti nama lengkap, tanggal lahir, alamat, nomor hp, email, dan password, kemudian klik daftar agar data tersimpan dalam database sistem.

c) Form Login Admin Cabang, digunakan sebagai media login admin cabang yang sudah mempunyai akun pada sistem dengan memasukan kode admin dan password yang sudah terdaftar dan tersimpan dalam database sistem.

d) Form Login Admin Sistem dan Owner, digunakan sebagai media login admin sistem dan owner yang sudah mempunyai akun pada sistem dengan memasukan kode admin dan password yang sudah terdaftar dan tersimpan dalam database sistem.

e) Form Input Kunjungan, digunakan sebagai media admin cabang untuk memasukan data kunjungan pelanggan yang datang ke barbershop menikmati layanan. Data kunjungan ini otomatis akan akan diolah menjadi laporan setiap bulan.

3) Kebutuhan Laporan hasil sistem Aplikasi AK-SQUAD, antara lain:

a) Laporan Data Kunjungan, yaitu sebuah laporan yang didalamnya terdapat data perkembangan kunjungan pelanggan yang ada pada setiap outlet barbershop. Dengan data ini manajemen bisa mengatahui outlet mana yang perkembangan kunjungan pelanggannya paling rame dan paling sepi, sehingga bisa langsung dicarikan solusi agar setiap outlet perkembangan kunjungan pelanggannya sama rata.

b) Laporan Data Pelanggan, yaitu sebuah laporan yang didalamnya terdapat data perkembangan pelanggan yang ada pada barbershop dibawah naungan manajemen SQUAD Corporation. Dengan data ini manajemen bisa mengatahui perkembangan pelanggannya cepat atau lambat, sehingga bisa dijadikan evaluasi agar data perkembangan pelanggannya selalu stabil. 
c) Laporan Data Master, yaitu sebuah laporan yang didalamnya terdapat data master seperti, data admin, data karyawan, data cabang, dan data layanan yang bisa dicetak apabila dibutuhkan.

\section{Tahap Design System}

Pada tahapan ini menggambarkan sistem basis data yang akan digunakan dengan ERD dan LRS, dilanjutkan mendesain System User Interface, dan Navigation Sturcture.

\section{a. Entity Relationship Diagram (ERD)}

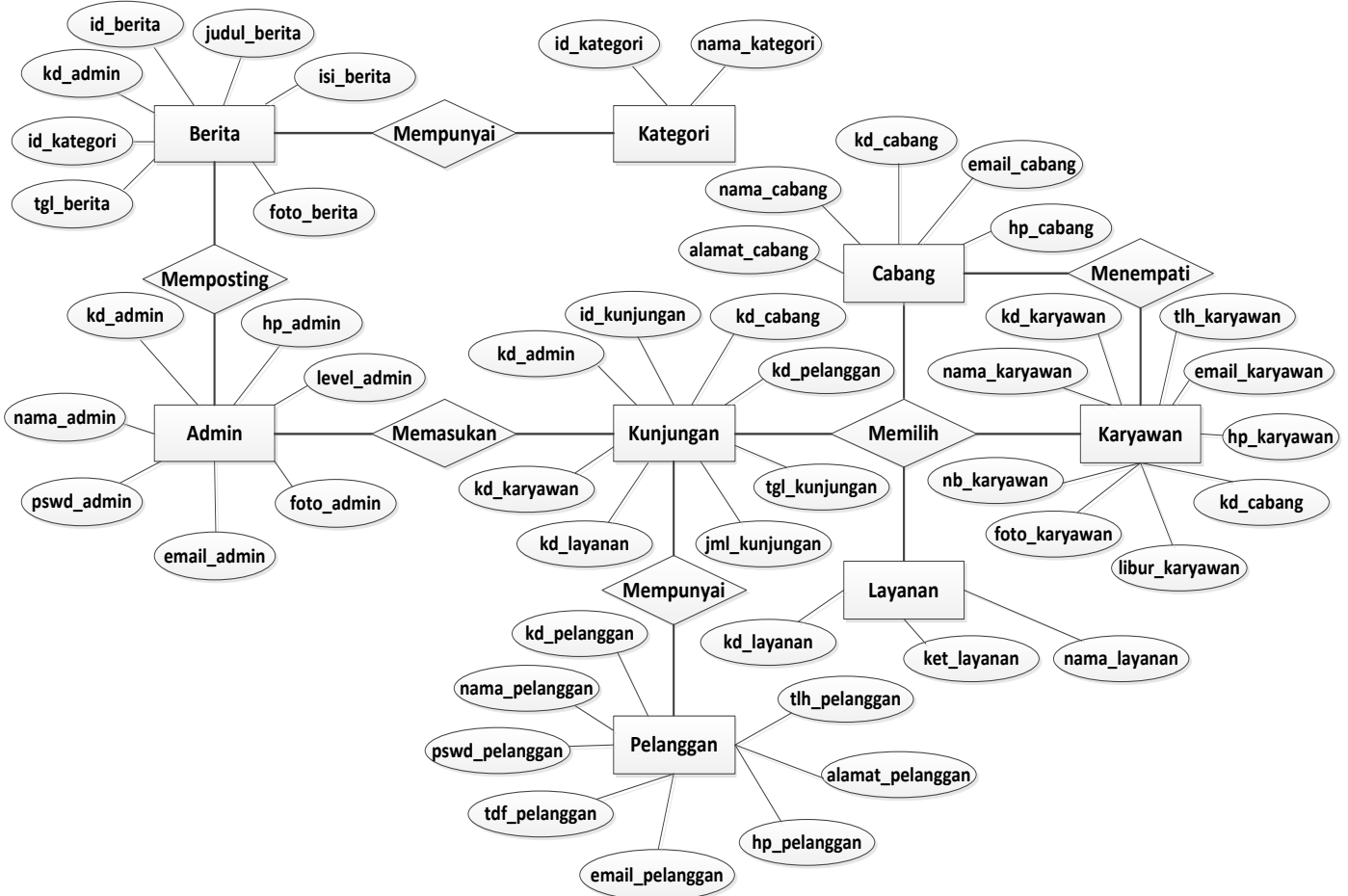

Sumber: Hasil Olah Data (2019)

Gambar 2. ERD Basis Data Aplikasi AK-SQUAD 


\section{b. Logical Record Structure (LRS)}

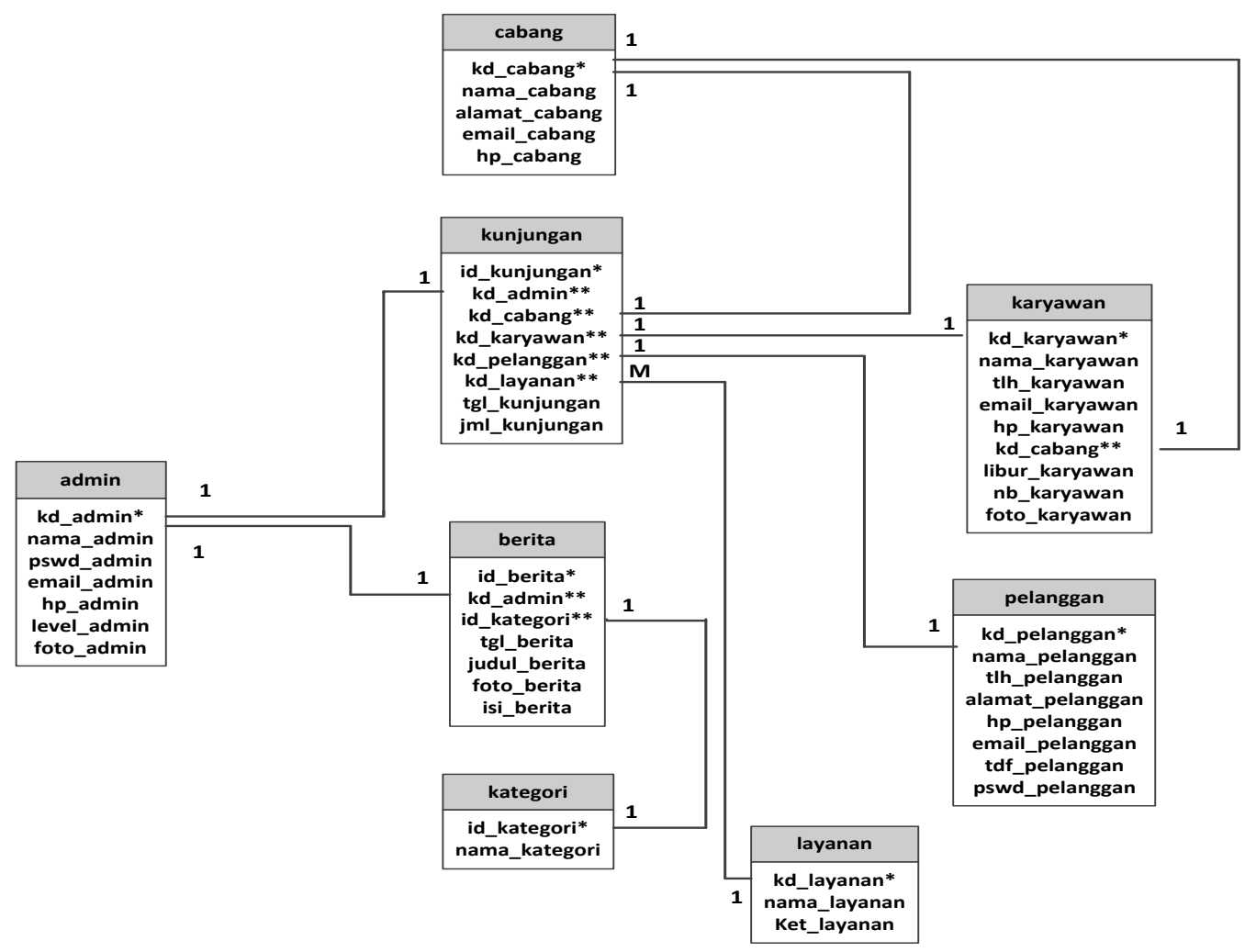

Sumber: Hasil Olah Data (2019)

Gambar 3. LRS Basis Data Aplikasi AK-SQUAD

c. System User Interface

1) User Interface Beranda Visitor

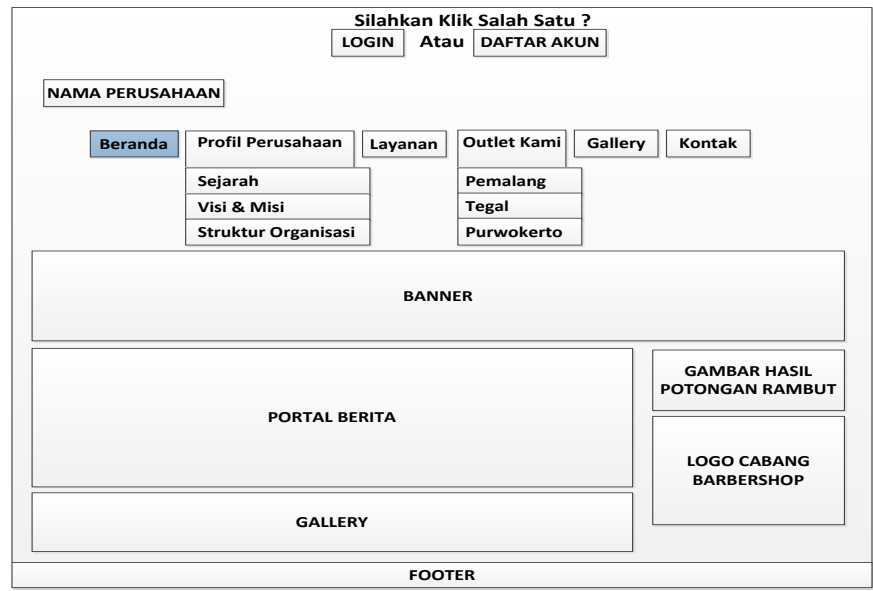

Sumber: Hasil Olah Data (2019)

Gambar 4. User Interface Beranda Visitor 
2) User Interface Halaman Login Pelanggan

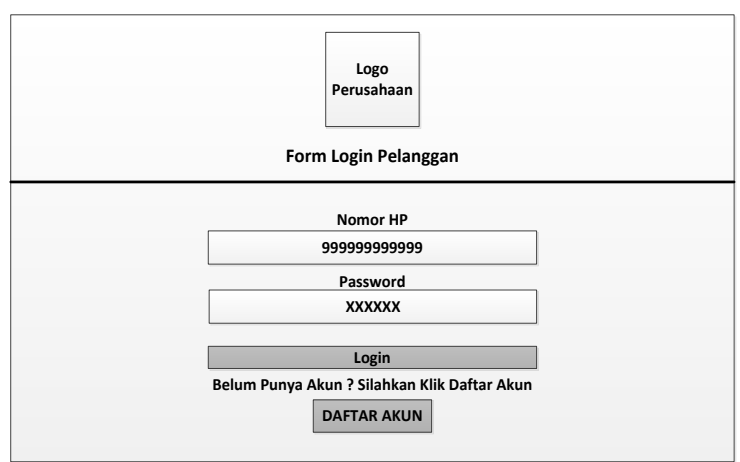

Sumber: Hasil Olah Data (2019)

Gambar 5. User Interface Halaman Login Pelanggan

3) User Interface Halaman Pendaftaran Pelanggan

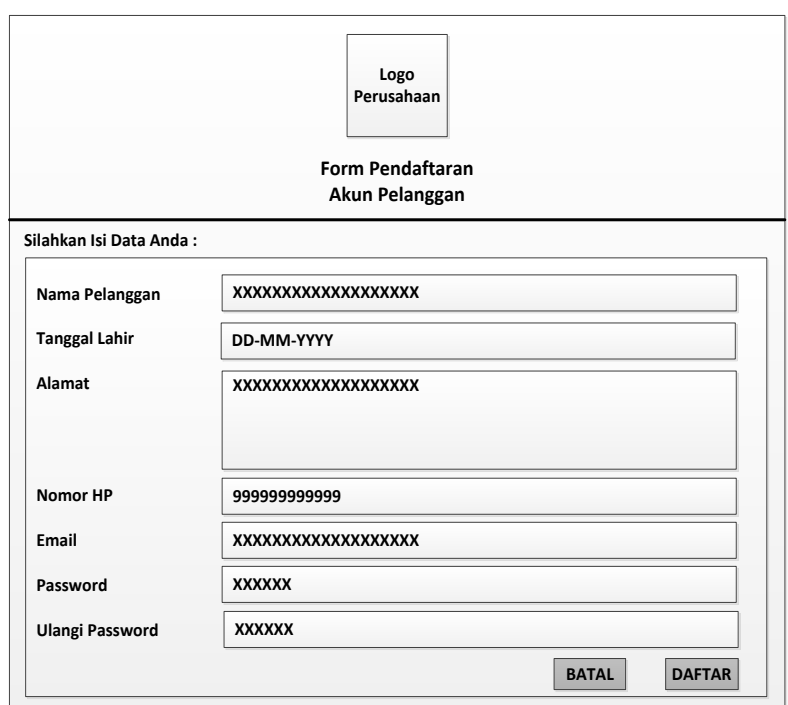

Sumber: Hasil Olah Data (2019)

Gambar 6. User Interface Halaman Pendaftaran Pelanggan

4) User Interface Halaman Lihat Kunjungan Per Pelanggan

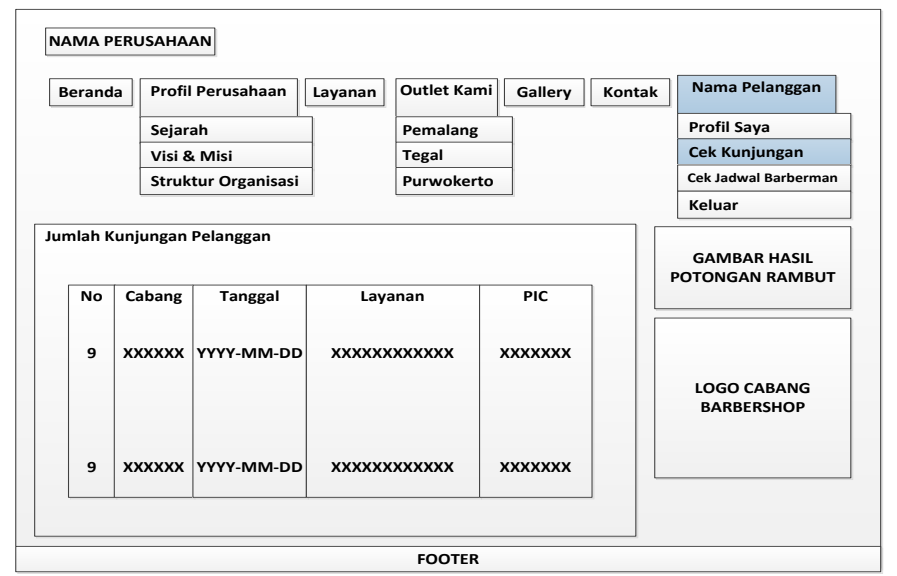

Sumber: Hasil Olah Data (2019)

Gambar 7. User Interface Halaman Lihat Kunjungan Per Pelanggan 
5) User Interface Halaman Input Kunjungan (Admin)



Sumber: Hasil Olah Data (2019)

Gambar 8. User Interface Halaman Input Kunjungan (Admin)

6) User Interface Halaman Lihat Data Pelanggan (Admin \& Owner)

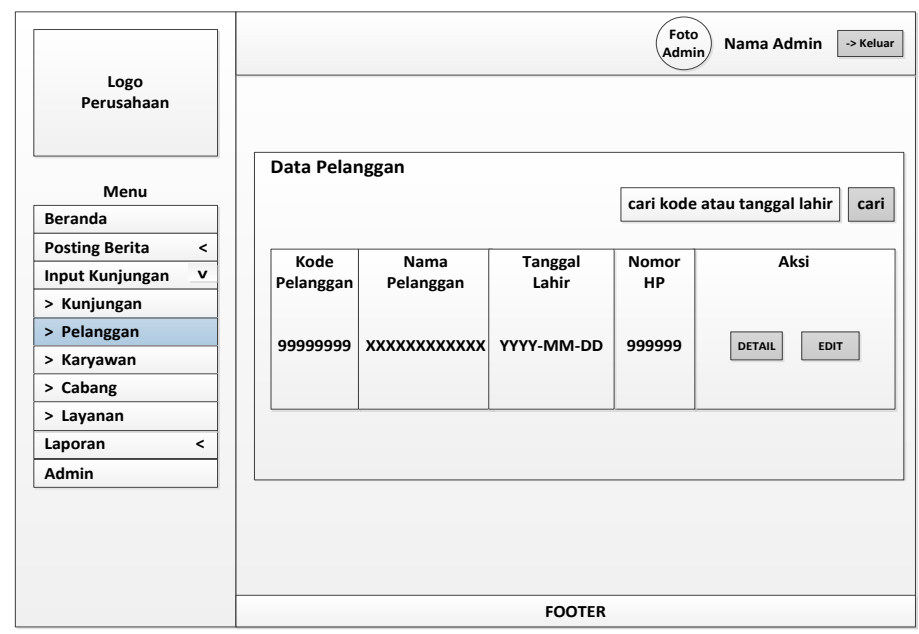

Sumber: Hasil Olah Data (2019)

Gambar 9. User Interface Halaman Lihat Data Pelanggan (Admin \& Owner)

7) User Interface Laporan Data Kunjungan (Admin dan Owner)

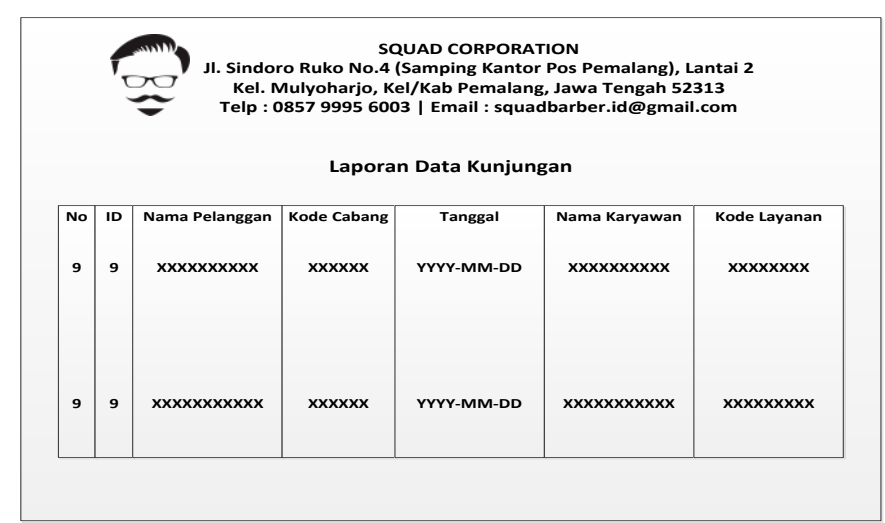

Sumber: Hasil Olah Data (2019)

Gambar 10. User Interface Halaman Lihat Data Pelanggan (Admin \& Owner) 
IJSE - Indonesian Journal on Software Engineering, Vol.5, No. 2, Desember 2019, 22-33 pISSN: 2461-0690 I elSSN: 2714-9935

\section{d. Navigation Structure}

1) Navigation Structure Halaman Visitor

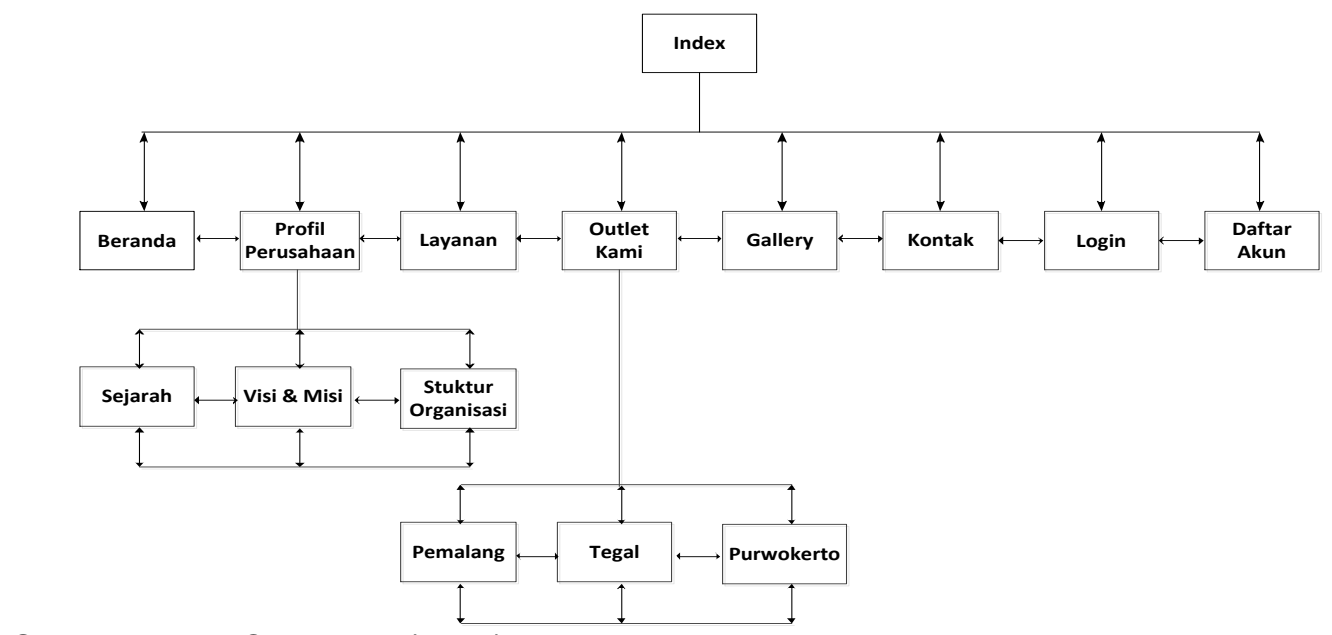

Sumber: Hasil Olah Data (2019)

Gambar 11. Navigation Structure Halaman Visitor

2) Navigation Structure Halaman Pelangan

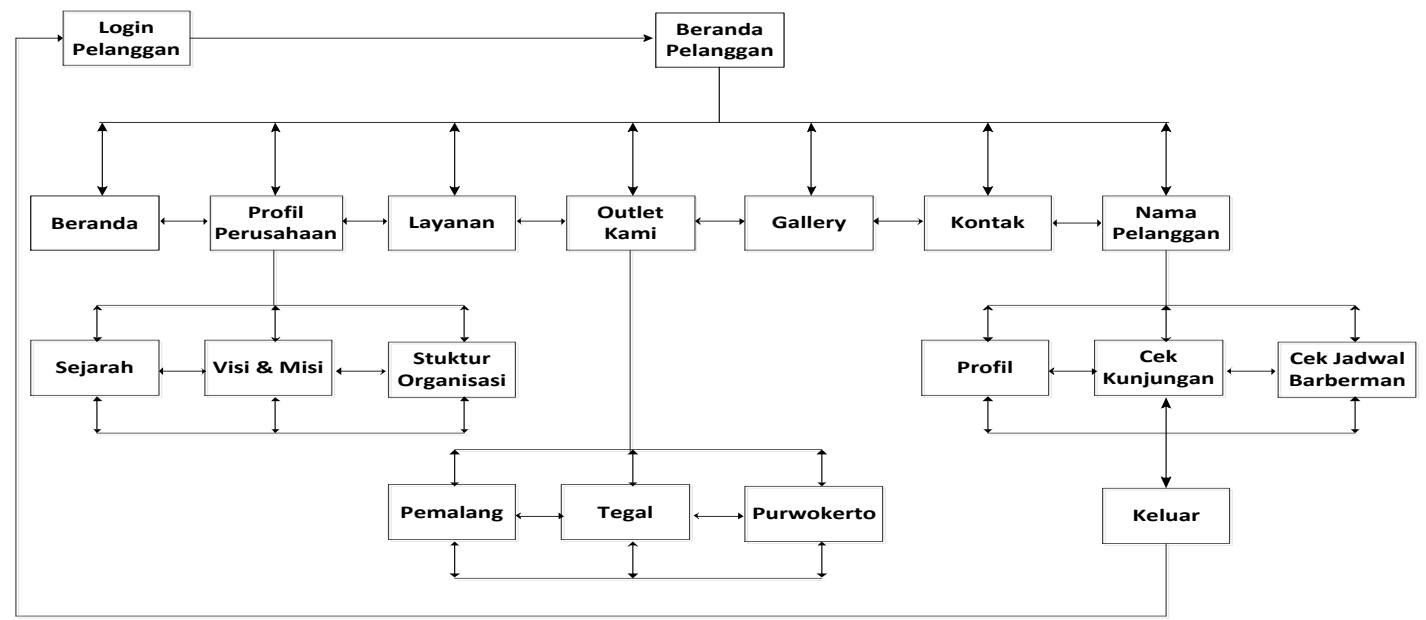

Sumber: Hasil Olah Data (2019)

Gambar 12. Navigation Structure Halaman Pelanggan

3) Navigation Structure Halaman Admin Cabang



Sumber: Hasil Olah Data (2019)

Gambar 13. Navigation Structure Halaman Admin Cabang 
4) Navigation Structure Halaman Admin Sistem

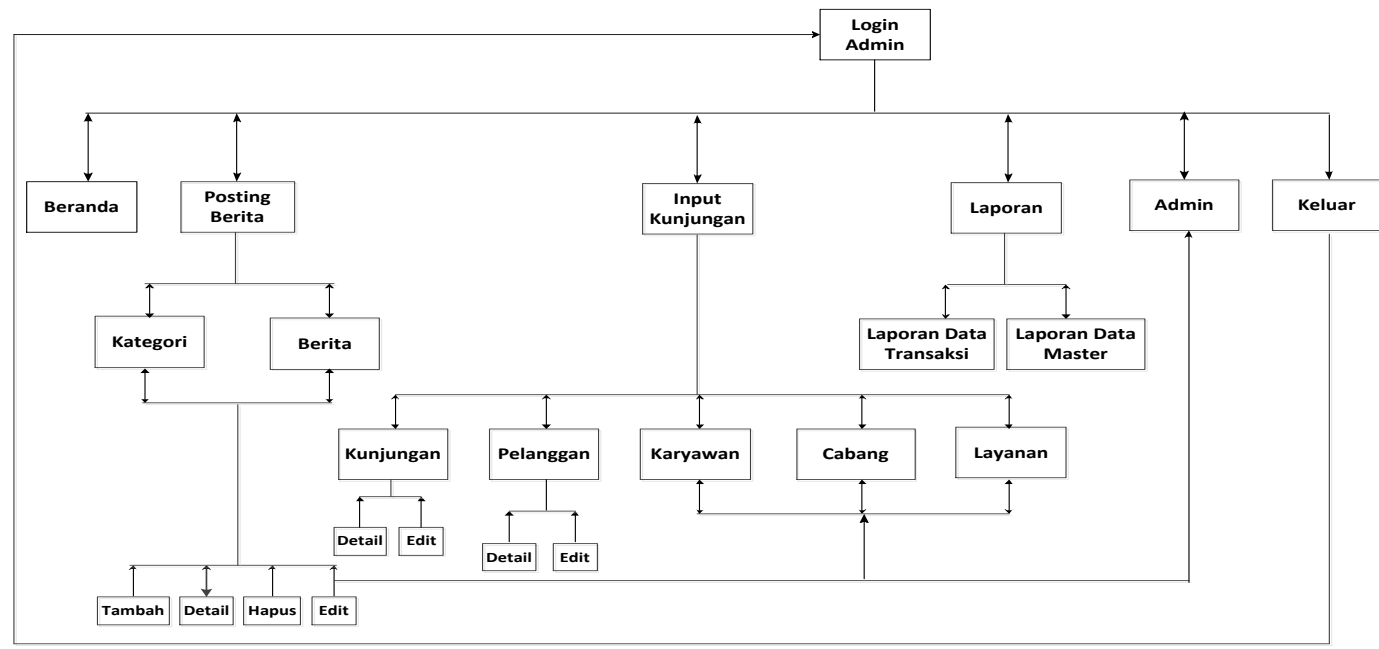

Sumber: Hasil Olah Data (2019)

Gambar 14. Navigation Structure Halaman Admin Sistem

5) Navigation Structure Halaman Owner

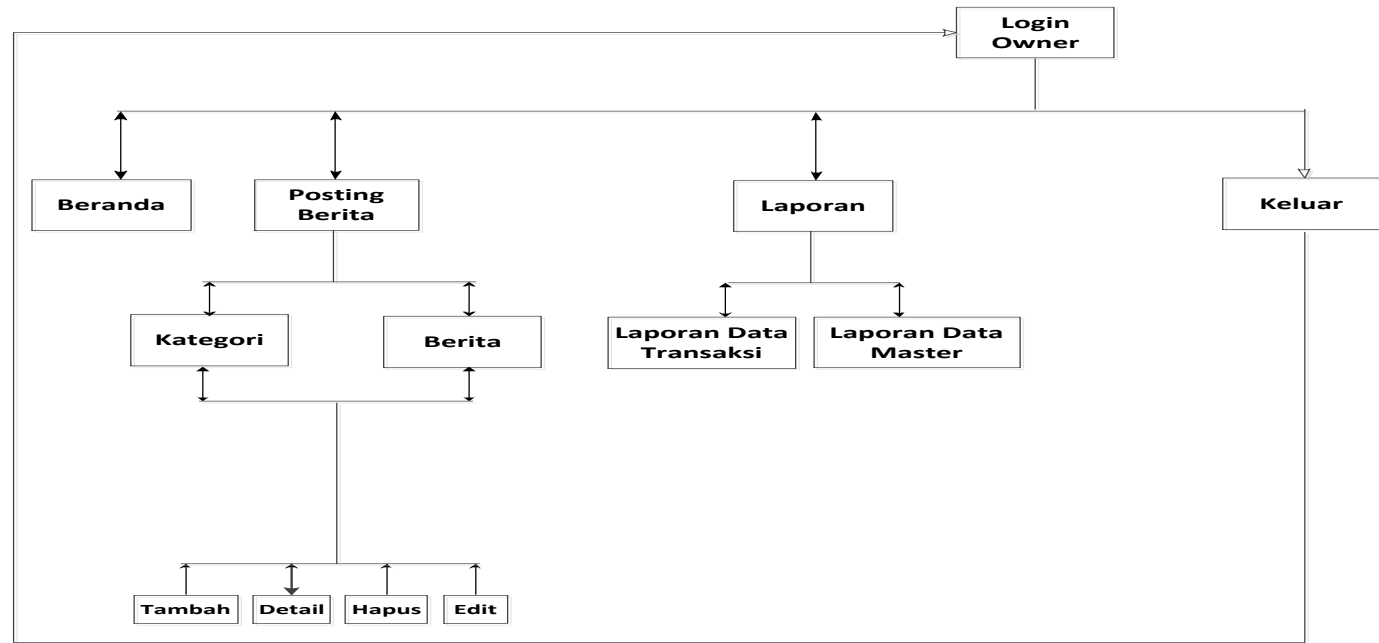

Sumber: Hasil Olah Data (2019)

Gambar 15. Navigation Structure Halaman Owner

\section{E. KESIMPULAN}

Berdasarkan pembahasan dari Perancangan Desain Aplikasi Manajemen Kunjungan Pelanggan Barbershop Squad Corporation (AK-SQUAD) dapat diambil kesimpulan, antara lain:

1. Aplikasi dapat dikatakan sebagai Sistem Informasi jika sistem tersebut mampu mengolah data masukan yang berasal dari transaksi harian dengan hasil laporan-laporan yang dapat digunakan oleh manajerial untuk membantu mengambil keputusan.

2. Metode pengembangan sistem Rapid Application Development (RAD) sesuai jika digunakan pada proyek sistem jangka pendek.

3. Desain Aplikasi Manajemen Kunjungan Pelanggan Barbershop Squad Corporation (AKSQUAD) dapat menjadi bahan acuan bagi pemrogram atau peneliti lain untuk membangun sistem informasi manajemen kunjungan pelanggan yang berguna untuk manajerial. 
IJSE - Indonesian Journal on Software Engineering, Vol.5, No. 2, Desember 2019, 22-33 pISSN: 2461-0690 I elSSN: 2714-9935

\section{REFERENSI}

Alfin, M. R., \& Nurdin, S. (2017). Pengaruh Store Atmosphere Pada Kepuasan Pelanggan Yang Berimplikasi Pada Loyalitas Pelanggan, 1(2), 249-258.

Brandenburg, L. (2018). How to Create an Entity Relationship Diagram (ERD). Retrieved November 11, 2018, from http://www.bridging-the-gap.com/erd-entity-relationship-diagram/

Darmawan, D., \& Fauzi, K. N. (2013). Sistem Informasi Manajemen. (A. Kamsyach, Ed.) (Pertama). Bandung: PT Remaja Rosdakarya.

Faqih, H., \& Avisha, T. D. (2017). Pendekatan RAD Dalam Perancangan GIS Penyebaran Penyakit (Studi Kasus: Puskesmas Kaligangsa Brebes). IJSE - Indonesian Journal on Software Engineering, 3(2), 1-7. Retrieved from http://ijse.web.id/

Firmansyah, R. (2017). Web Klarifikasi Berita Untuk Meminimalisir Penyebaran Berita Hoax, 4(2), 230-235.

Ma'rifati, I. S. (2015). Sistem Informasi Akuntansi Pendapatan Sumbangan Pembinaan Pendidikan (SPP) Pada SMU XYZ. Jurnal Evolusi, 3(1), 1-8. https://doi.org/10.1103/PhysRevE.71.036411

Malau, Y., \& Ariyanto, A. S. P. A. (2014). Implementasi Sistem Pelayanan Pendaftaran Haji Dan Umroh Online Pada Pt . Mandiri Mawaddah Nusantara. Bianglala Informatika, 2(1), 43-62. Retrieved from https://ejournal.bsi.ac.id/ejurnal/index.php/Bianglala/article/view/567

Ratnawati, Siwi, D. R., \& Faqih, H. (2018). Pendekatan Rapid Application Development Dalam Merancang Program Administrasi Klinik (Studi Kasus:Klinik Anugerah Sehat). Journal Speed-Sentra Penelitian Engineering dan Edukasi (Vol. 10).

Rohman, R. S., Ermawati, E., Farlina, Y., \& Syabaniah, R. N. (2018). Rancang Bangun Web ELearning Untuk Pengelolaan Mata Pelajaran TIK Pada SMPIT, 6(1), 85-90.

Setyanta, B. (2017). Anteseden dan Konsekuensi dari Kepuasan Pelanggan : Survei Kepuasan Pelanggan Barbershop di Yogyakarta, 3(1), 29-44.

Wahyuningrum, T., \& Januarita, D. (2014). Perancangan WEB e-Commerce dengan Metode Rapid Application Development ( RAD ) untuk Produk Unggulan Desa. Seminar Nasional Teknologi Informasi Dan Komunikasi, 9(November), 81-88. Retrieved from https://publikasi.dinus.ac.id/index.php/semantik/article/view/829

Wijaya, G., \& Sari, M. (2015). Perancangan Sistem Informasi Pengajuan Kredit Berbasis Web Pada PT . BPR Kredit Mandiri Indonesia Cabang Bekasi. IJSE - Indonesian Journal on Software Engineering, 3(2), 98-104. 